\title{
Use of Linguistic Qualifiers and Intensifiers in a Computer Conference
}

\author{
Patrick J. Fahy \\ Centre for Distance Education \\ Athabasca University
}

\begin{abstract}
Previous research in text-based computer conferencing has reported that analysis of transcripts of online discussions can reveal how participants network socially, exchange information, and attempt to construct knowledge. Some have detected gender differences in online discussions, which may affect the interpersonal dynamics within the group. This study investigated a possible gender-related communications difference (the use of linguistic qualifiers and intensifiers) in a computer conference transcript. The study differed from some previous work in using the sentence as the unit of analysis and in employing a newly developed tool for coding, the Transcript Analysis Tool. Results suggested a tendency for women to use more of the forms thought likely to sustain dialogue (qualifiers, conditional and parenthetic statements, and personal pronouns), whereas men's postings generally contained fewer qualifiers and more intensifiers. The differences were seen as generally supporting previous findings and also as demonstrating that in a moderated conference the range of interactive behavior is less extreme than in "open" or unstructured environments.
\end{abstract}

Online conferencing is increasingly central to much distance education and training. Tutors and students use conferences to create and sustain relationships online, and students interact with each other and with information in conferences. Research in this area is aided by the wealth of online data generated (conference transcripts and $\log$ files detailing the interaction), which, with proper analysis, can aid in understanding the unique nature of computer-mediated communications (CMC; Collot and Belmore 1996; Garrison, Anderson, and Archer 2001).

Requests for reprints should be sent to Patrick J. Fahy, Centre for Distance Education, Athabasca University, 1 University Drive, Athabasca, Alberta, Canada T9S 3A3. E-mail: patf@athabascau.ca 
I have critiqued some previous transcript analysis work for various methodological weaknesses (Fahy 2001a) and with colleagues have suggested an alternative methodology and instrument (the Transcript Analysis Tool, TAT) for exploring interaction and social network patterns (Fahy, Crawford, and Ally 2001). This study extends previous work, in accord with the view of the impact and efficacy of CMC as dependent both upon the content of the interaction and the quality of the interpersonal environment in which it occurs (Collins and Berge 1996). The subject in this study was an analysis of the communications of men and women in an online computer conference moderated by the course instructor as part of a graduate course in distance education. The particular focus was the students' use of various linguistic forms thought to be gender related, which tend to extend (epistolary forms) or limit (expository forms) ongoing interaction in an online conference.

\section{Theoretical Context}

Various ways in which men and women differ in their typical communication styles have previously been described (Kirkup and von Prummer 1990; Herring 1996; Savicki, Lingenfelter, and Kelley 1996). In unmoderated, "open" online conferences and listservs, for example, men have been found to be more assertive, argumentative, and aggressive, whereas women were more "caring, sociable, and hence interactive" (Herring 1996; Yates 1996; Rodino 1997). Other observations, such as that men tend to be more engaged with online communication than women (Blocher 1997) or that women have fewer opportunities for online access (King 1998), have been less well supported or rejected in more recent studies (Fahy, Crawford, and Ally 2001).

Online text-based communication has been recognized as an entity with unique characteristics - not merely a "pale shadow" of spoken language (Garrison, Anderson, and Archer 2001) but a form of "talking in writing" that shares elements of both written and spoken communication (Collot and Bellmore 1996). Text-based CMC is a vehicle through which participants are potentially able to create "social presence" (a projection of their personalities as well as their ideas) if given proper guidance and structure (Garrison, Anderson, and Archer 2000).

The growth in conferencing has encouraged transcript studies (Hillman 1999). As more work has been done in this area, methods have been refined and results have generally tended to be more illuminating of and applicable 
to the processes and the content of online interaction, though suggestions for improvements in methods and theory-building efforts have also been made (Saba 2000; Fahy 2001a).

Among the earliest efforts at transcript analysis was Henri's (1992), who viewed CMC as a "gold mine of information regarding the psychosocial dynamics at work among students" (118). Henri rightly saw that online communication was more than simply a means of conveying information; she demonstrated that the interactive process itself and the dynamics of group communication were seen by participants as central to their learning. Henri's model of content analysis considered what she called the "social osmosis" in the group (120), including the circulation of ideas and the connections established among individuals. She recognized that "merely" social factors such as the multiple views expressed in group exchanges, the reduction of social pressure resulting from conversational opportunities, and the feelings of belonging to the group resulting from successful collaboration could together contribute significantly to the learning value of CMC (119).

To address more of the social milieu in conferences, especially what she termed the metacognitive components of online content and processes leading to useful learning, Henri (1992) constructed a qualitative analytic tool that identified five dimensions of online interaction: participative, social, interactive, cognitive, and metacognitive (124). Henri divided (the unlovely current term is "unitized") her transcript into meaning units rather than using a more structurally grounded unit of analysis such as the sentence or even the paragraph. Although others subsequently chose the sentence as a less subjective unit of analysis (Hillman 1999; Fahy 2001a), some followed Henri's lead in using nonsentence units: Gibson (1996) attempted to find "speech segments" in her corpus; Gunawardena, Lowe, and Anderson (1997) adopted Henri's "meaning units"; and Anderson et al. (2001) and Garrison, Anderson, and Archer (2001) used "message units" (though they conceded that they would consider using "sub-message units" [i.e., sentences] in future work).

Overall, although Henri's (1992) approach left unanswered questions about the metacognitive aspects of online interaction, her perceptions about the place of interactivity in online communications were useful. For purposes of this study a key insight was the observation that consideration of interactive content plus other data was needed to create a clear understanding of the collaborative processes at work in online learning situations (128). 
Zhu's (1996) interest in transcript analysis was in the processes of meaning negotiation and knowledge construction at a distance. She approached the task with the assumption that "electronic conferencing promotes student-centered learning" (822) and that it was important for students to engage in collaborative and self-regulated activities, including reflection, in the social context of the conference (823).

Zhu (1996) studied the transcript of a graduate-level course. Her analytic framework identified vertical and horizontal interactions (those that acknowledged a superior source of information or advice and those for which there was no authoritative source or correct answer, respectively). Her method involved counting occurrences of questioning, information exchange, reflection, and knowledge construction. Zhu concluded that individuals were motivated to construct knowledge by their interactions with others and that she was able to discern assimilation in the processing of information by participants (840).

Zhu's (1996) work was significant in two ways. First, she simplified the process of analyzing the conference by limiting her instrument to five categories: questions, reflections, discussion, comments, and answers (824). Other analytic approaches had used up to twenty coding categories, and instruments with over a dozen categories were not uncommon (Fahy 2001a). Second, Zhu recognized that participants' relationships to one another were mirrored in their interactions: the interaction reflected information about the social network and conveyed content about the topic under discussion. The act of asking a vertical question, for example, was both a request for information and an acknowledgment that the person approached was likely to possess the answer and thus to occupy the superior social status of a potential advisor or knowledge provider. Using Zhu's typology to reveal the patterns of interaction in a conference could help describe the structure of the supporting social system and form an example of some of the "other data" Henri (1992) had mentioned as important to full understanding of the collaborative process.

The processes by which knowledge might be constructed in a moderated online debate were explored by Gunawardena, Lowe, and Anderson (1997). Following Henri's advice, they attempted to identify "meaning units" within the interaction. The resulting analysis placed over $90 \%$ of the postings in a single category ("sharing, comparing information"), indicating an apparent lack of discriminant capability in the instrument (Fahy 2001a). Methodological problems aside, Gunawardena, Lowe, and Anderson's work contained an important observation: 
Interaction should be viewed as the totality of interconnected and mutually responsive messages, which make up the conference, and perhaps more: interaction is the entire gestalt formed by the on-line communications among the participants. The participants are not speaking in the same virtual space by chance and regardless of each others' presence; they are acting in relation to each other and in a manner which reflects each others' presence and influence. They are not merely acting, nor reacting, but interacting, even if the links among individual messages may not be readily apparent. (405)

The concept of the gestalt of the communication and the importance of the "totality" of the content and the interaction are insightful. Like Henri's (1992) "other data," assessment in some systematic way of the totality of the conference could be seen as key to understanding its importance in the learning process. Seeing the totality of the interaction implies looking beyond single elements of conference content or interaction, viewing the interaction as at least partially a social network transaction and recognizing the resulting communication as a reflection of interpersonal as well as intellectual engagement (Fahy, Crawford, and Ally 2001).

Garrison, Anderson, Rourke, and Archer in a series of important papers (Rourke et al. 1999, 2001; Garrison, Anderson, and Archer 2000, 2001; Rourke and Anderson 2000; Anderson et al. 2001) examined CMC as a record of the striving of an online community to achieve higher-order learning outcomes through the creation of cognitive, social, and teaching presence. Their work has contributed to the context for transcript studies and has suggested a useful a framework for considering the observable elements of online communication. Especially helpful for this study (discussed further later) was their concept of social presence, the act of projecting one's personality onto the online community through textual and linguistic devices.

Gender has emerged as an explanation of the types of linguistic forms and strategies participants choose in projecting social presence in online networks. Herring (1996) found in her studies of transcripts from listservs and other unmoderated forums that men were "more assertive and argumentative," tending to challenge and criticize others, attracting attention to themselves, and engaging in "contests" intended to gain status in the online community (104). The male "expository" style also claimed to value information more highly, sometimes using accusations of "insufficient informativity" to terminate interaction with those with whom there was disagreement (105). 
The female "epistolary" participation style, on the other hand, was found by Herring (1996) to include more efforts to continue dialogue and to avoid confrontation. Epistolary interactions emphasized commonalities between participants rather than differences and were more likely to view interlocutors as aligned than opposed. The epistolary style was seen as more referential of the other participants, attempting to weave consensus from the individual contributions of the group.

Weaker links between gender and interactive styles than those found by Herring (1996) have been reported. In a study of a wide variety of unmoderated, "open" online discussion groups, Savicki, Lingenfelter, and Kelley (1996) found only limited gender associations. They did concede that women's groups tended to contain more self-disclosure and more attempts at tension reduction, whereas men's groups included more fact- and action-oriented statements, but their analysis failed to find more questions, opinions, apologies, or first-person pronouns in women's groups or instances of rudeness or aggression in the contributions of men. Although they reported that men- or women-only (unisex) groups were more likely to feature extreme gender-associated behavior, Savicki, Lingenfelter, and Kelley concluded that the gender composition provided only modest explanatory power for any interaction differences observed in their groups.

In our previous work (Fahy, Crawford, and Ally 2001), we found that some of Herring's (1996) findings regarding gender preferences for epistolary and expository linguistic forms held, namely, that women asked and answered questions more often and that women were more interested in and involved with social network functions of the online community, making more contacts within the network and responding more often to the overtures of others (their rates of ignoring others, or failing to include others among their personal contacts, were half those of men; Ridley and Avery 1979; Fahy 2001b). We also found that women more frequently employed characteristic epistolary conventions such as signing their postings and retaining the message titles of others when responding.

Overall, these findings suggest some apparent gender differences in typical online communicative styles and strategies. The present study sought to determine whether gender differences in the use of language to qualify or intensify participants' postings, frequently observed in open and unmoderated discussions, might be detected in the more structured environment of a course conference moderated closely by the instructor. 


\section{Methodology}

The focus of the enquiry was on the participants' uses of linguistic qualifiers and intensifiers, as found in the transcript of a fifteen-week graduate course in distance education. Based on previous findings related to gender and language use in online communications discussed earlier, it was hypothesized that men's and women's preferred online interaction styles would differ in relation to use of qualifiers and intensifiers as follows:

- The dominant female style would be more epistolary, using more hedges ("sort of," "kind of," "perhaps," "it seems to me") and qualifiers ("I think," "perhaps"); more first- and second-person pronouns, to emphasize the interpersonal element of the online exchange (Yates 1996); and more conditional (if-then) and parenthetic expressions, as ways of reducing potential conflict, softening disagreement, expressing tentativeness, and sustaining dialogue.

- Consistent with lesser concern for continuing dialogue, the male $e x$ pository style would be expected to use fewer of the previously mentioned dialogue-sustaining forms and would be more emphatic and declamatory. In addition to using more intensifiers ("certainly," "of course," and "very"), men would be expected to be generally less civil and, in extreme cases, even to engage in flaming, coarse language and other forms of rudeness.

A transcript consisting of 356 student postings (44,599 words in 2,558 sentences) was examined. (The instructor contributed an additional 9000 words in 102 postings; these were ignored in this analysis). ATLAS.ti (ver. 4.1), a computer-based qualitative research tool, and SPSS-PC were used to code and subsequently analyze the data. Coding was accomplished on a sentence-by-sentence basis by the author. It was not felt that reliability needed to be checked in this analysis as the linguistic items of interests were relatively unambiguous, and not, as is often the case in transcript research, subject to interpretation (Fahy 2001a).

The student group was relatively small (13 students, 7 male, 6 female). The students were aware that their conference transcript would be the object of research, and participants had been guaranteed complete privacy in any reports. In consideration of any anxiety the participants might have regarding the proposed research, students were offered the option of an alternate activity if they did not wish to participate, and until the end of the course they could withdraw or edit any posting they had made. No student 
elected the alternate activity, and no one requested that a posting be withdrawn or edited.

\section{Findings}

\section{Qualifiers and Intensifiers}

Table 1 shows differences in the use of the seven most commonly occurring qualifiers found in the transcript (those that occurred thirty or more times). Shown are the totals for men and women, the proportion of usage of each term by men and women, and, to permit comparisons, the occurrence of each term per 1000 words. (Men [ $n=7]$ posted a total of 20,804 words, women $[n=6] 23,795$. See Fahy, Crawford, and Ally 2001 for a full description of the content of the transcript in relation to the TAT.)

The results for qualifiers were mixed: women used $57 \%$ of the qualifiers overall, and their rate of usage ( 15 per 1000 words) was about $15 \%$ greater than the men's (13 per 1000); however, men's rates of usage slightly exceeded the women's on three of the seven most commonly occurring qualifiers ("may/might," "often," and "probably"). The largest difference was for the qualifying phrase "I think," $68 \%$ of the total uses of which were by women.

Overall, intensifiers were less than half as common as qualifiers in the transcript (there were a total of 252 intensifiers, compared with 620 qualifiers). Table 2 shows the five most commonly occurring intensifiers found in the transcript.

Although the results were again mixed, they were also suggestive of a pattern supporting the hypothesis of men's greater use of intensifiers:

- Men's uses of intensifiers exceeded women's on four of the five items listed.

- Men produced $61 \%$ of all intensifiers.

- Men's sentences averaged more than 50\% more intensifiers than women's. (The ratio of qualifiers to intensifiers was 1.7:1 for men and 2.6:1 for women.)

- The most commonly used intensifier, "very," occurred almost twice as often in men's posting as in women's. 
Table 1. Occurrence of Qualifiers Appearing 30 Times or More

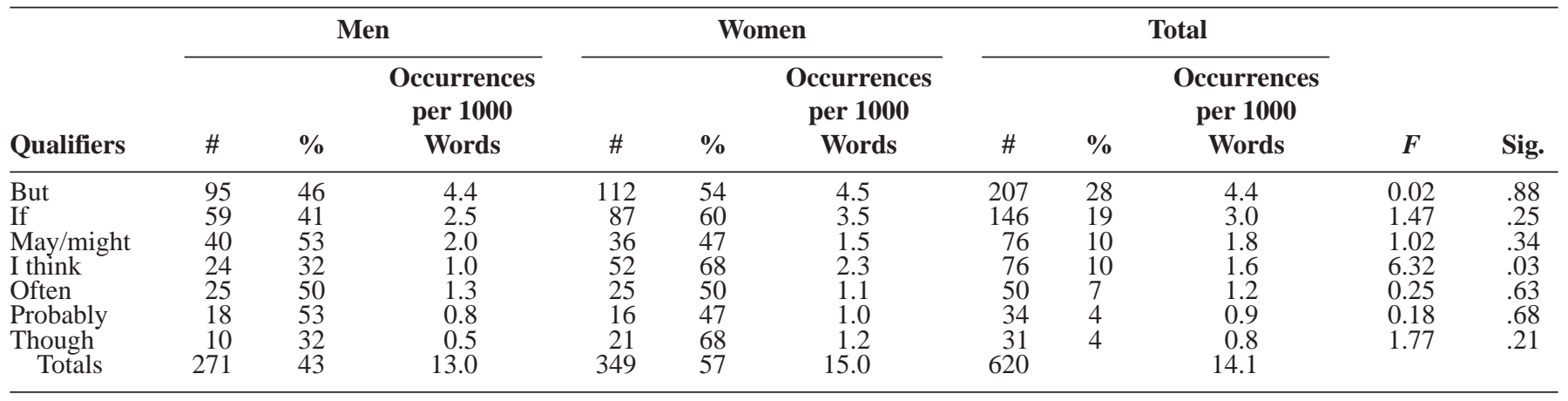

Note: $\quad$ Sig. = statistical significance of the $F$ value. 
Table 2. Occurrence of the 5 Most Commonly Used Intensifiers

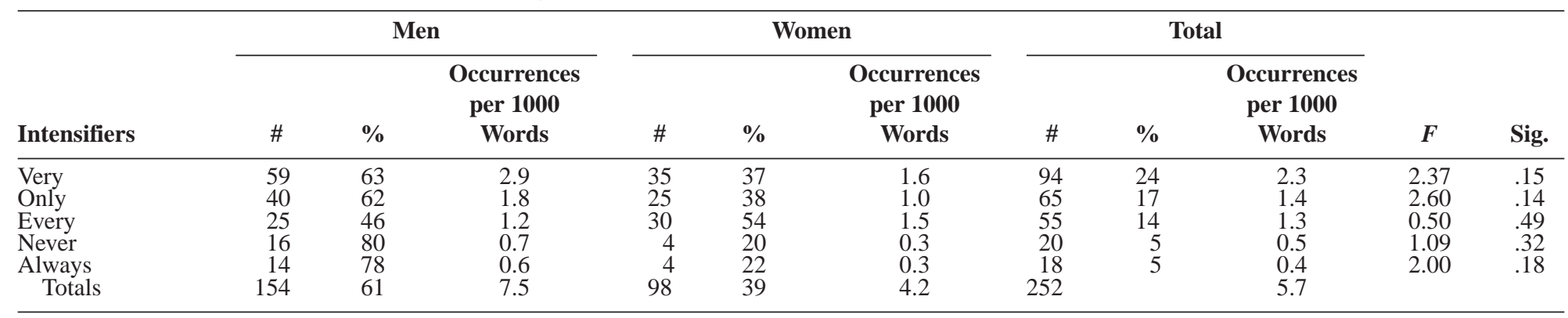

Note: $\quad$ Sig. $=$ statistical significance of the $F$ value. 


\section{Parenthetics, Conditional Expressions, and Pronoun Usage}

Parenthetic and conditional expressions (chiefly if-then constructions, but also including comparatively rare subjunctive forms of the types should it be or if it were) were seen as another way of softening any potential opposition to the message, parenthetics by adding "by the way" material (in the self-effacing manner of parenthetic expressions), and conditionals by suggesting assertions were somehow contingent. The pronouns $I$ and you were seen as reflecting a preference for personal (epistolary) interaction. Table 3 shows the occurrence of parenthetic and conditional expressions and the use of pronouns by men and women.

Again, findings were suggestive, if not emphatic. Women used $65 \%$ of the characteristically epistolary parenthetic expressions and $54 \%$ of the conditionals overall. Regarding the pronouns, women used $I$ and you more than the men. Pronouns have been found to occur proportionally more often in CMC than in writing or speech (Yates 1996). In some contexts (i.e., journalism), $I$ is associated with personal speech and with "self-centered articles by people of note, ... investigative reporting, and ... eye-witness accounts" (Yates 1996, 40), whereas diminished use of the personal pronoun reflects greater social impersonality. Low frequency of personal pronouns (more common here in the men's postings) is associated with more informational prose (Collot and Belmore 1996).

\section{Discussion}

Savicki, Lingenfelter, and Kelley (1996) concluded from their data that gender was not a powerful predictor of participants' online behavior. On the basis of only the statistical evidence, the same conclusion might appear to hold here, too. Also, some forms of extreme behavior observed in open conferences (rudeness, coarse language, dismissive, sexist, or suggestive comments) were not observed here. Nevertheless, the findings were suggestive and salient in relation to the question of gender styles in online communication.

Specifically, trends in the data consistent with previously reported gender associations included the following:

- Women used more qualifiers: women had higher totals and higher rates of usage of qualifiers than did men; although both men and women used more qualifiers than intensifiers, women's preference for qualifiers 
Table 3. Parenthetics, Conditionals, and Pronoun Usage

\begin{tabular}{|c|c|c|c|c|c|c|c|c|c|c|}
\hline \multirow[b]{2}{*}{$\begin{array}{l}\text { Linguistic } \\
\text { Elements }\end{array}$} & \multicolumn{3}{|c|}{ Men } & \multicolumn{3}{|c|}{ Women } & \multicolumn{2}{|c|}{ Totals } & \multirow[b]{2}{*}{$\boldsymbol{F}$} & \multirow[b]{2}{*}{ Sig. } \\
\hline & \# & $\%$ & $\begin{array}{c}\text { Occurrences } \\
\text { per } 1000 \\
\text { Words }\end{array}$ & $\#$ & $\%$ & $\begin{array}{c}\text { Occurrences } \\
\text { per } 1000 \\
\text { Words }\end{array}$ & \# & $\begin{array}{c}\text { Occurrences } \\
\text { per } 1000 \\
\text { Words }\end{array}$ & & \\
\hline Conditionals & 36 & 46 & 1.6 & 43 & 54 & 1.9 & 79 & 1.7 & 0.28 & .60 \\
\hline Parenthetics & 81 & 35 & 3.6 & 151 & 65 & 5.7 & 232 & 4.6 & 2.56 & .14 \\
\hline \multicolumn{11}{|l|}{ Pronouns } \\
\hline I & 424 & 41 & 18.8 & 606 & 59 & 25.7 & 1030 & 22.0 & 3.28 & .10 \\
\hline $\mathrm{We}$ & 149 & 48 & 6.6 & 159 & 52 & 7.2 & 308 & 6.9 & 0.66 & .80 \\
\hline Us & 27 & 54 & 1.2 & 23 & 46 & 1.1 & 50 & 1.2 & 0.03 & .87 \\
\hline You & 95 & 38 & 4.1 & 158 & 62 & 6.9 & 253 & 5.4 & 7.56 & .02 \\
\hline
\end{tabular}

Note: Sig. = statistical significance of the $F$ value. 
was more than twice that of the men's (women used qualifiers 3.6 times more often than intensifiers, whereas men used them 1.7 times more often); women used almost two-thirds of all parenthetic expressions.

- Women preferred personal over collective language: women's usage of the pronouns I and you exceeded men's by $25 \%$ and $44 \%$, respectively, whereas men's uses of the collectives we and us were greater.

- Men used more intensifiers: men used the most commonly occurring intensifiers $64 \%$ more than women despite writing $13 \%$ fewer words, and men used the two most common intensifiers (very and only) $61 \%$ more than women.

Although the results obtained here form a pattern and seem to indicate a tendency for gender preferences in communication styles, the findings were less emphatic than had been reported by others. Examination of the circumstances under which this transcript was generated suggested possible explanations for the discrepancies.

First, this study used online interactions generated in a structured and moderated conference in which the instructor was highly involved (the instructor contributed about $25 \%$ of the postings and $20 \%$ of the words in the transcript). Observers of online interaction (French et al. 1999) have attested to the impact of moderation on outcomes in online interaction. Although the association between instructor presence and specific outcomes is not yet well understood (Anderson et al. 2001), it is plausible that the instructor's presence was at least partially responsible for the consistently high levels of civility maintained.

Second, and related to the previous explanation, there was a high level of instructor-imposed task in this conference (Savicki, Lingenfelter, and Kelley 1996). The group task (defined as work that requires collaboration and cooperation, such as solving a problem or discussing or generating ideas) consisted of topics provided by the instructor. To be successful, the group needed to work effectively together. In listservs and other open environments no such requirement for cooperation exists. In unmoderated situations, the payoff for some participants appears to lie in deceiving, embarrassing, or upstaging others. Studies of group decision making have demonstrated the importance of imposed goals, criteria, roles, and rules both for task completion and for group function (DeSanctis and Gallupe 1987). The performance difference observed in this group may reflect the known principle that increased structure obviates inappropriate behavior in task-oriented situations. 
A third factor was the maturity of the group itself and the homogeneity of their interests. The average age in the program from which this group was formed was forty-two years, and all were graduate students in the same program. It is likely that maturity, experience with online communications, and a sense of common purpose predisposed the participants to greater cooperation, especially, as noted previously, as the task-orientation of the group was also very high.

Finally, the participants who generated this transcript were not anonymous when posting to the conference. All postings in the study transcript contained the identity of the contributor on a "From" line, and aliases or pseudonyms were not permitted. Asocial forms of interaction (Abrami and Bures 1996) and the "hi-jacking" of conferences by disaffected or malicious participants (Collison et al. 2000) are more likely in unmoderated or anonymous situations where repercussions for such behavior may not exist.

\section{Conclusion}

Although the associations were not strong, indications of gender differences in the use of qualifiers and intensifiers appeared in the interaction studied here. Perhaps because they were subtle, the findings reinforced the importance of attending to nuances in the social environment as a way of increasing understanding of the dynamics of online group learning. Particularly in online group learning situations, social ambience is part of the learning gestalt. In this instance, different linguistic strategies seemed to characterize the behavior of men and women as they projected their social presence in the conference.

The findings also suggest the need for further research on factors of known importance to network function (such as group size, group task, and interaction opportunities) in relation to participant behavior. For example, would interaction patterns change if the group were larger or if the proportion of men and women were unequal? What impact does the presence and nature of a predefined task have on interaction patterns? Would prospect of meeting face-to-face change interaction patterns?

Continued study of online social and communicative behavior to answer these and other questions is important because online interaction is likely to remain central to the delivery of distance learning, and the tools for interacting online are becoming more powerful as bandwidth increases (Ball 2001; "Still time" 2001). Practitioners need to understand both the overt 
and the covert factors that affect learning in online situations. We may be alert to obvious violations of civility or fairness, but we are probably less aware of more subtle underlying influences in the environment, which may also impact the inclusiveness, appeal, and effectiveness of the online community for different participants.

Another reason for continued interest in the subtle linguistic patterns in conferences is to increase awareness and reduce instances of unfair treatment of nonexpository online participation. Participants of either gender who use the epistolary style may appear to some to be less task-oriented, especially compared to those interacting strictly in a narrow expository style. Use of epistolary strategies to focus on elements of group function, to maintain the social network, or to support the health of the online environment may be criticized as failing to address the informational purposes of the conference and may be dismissed for lack of informativity.

A counterposition might recognize that concern for the social and interpersonal in online communities is not "merely" social but supports the purpose of conferencing as an expression of cognitive engagement through social connections (Fulford and Zhang 1993; Anderson and Garrison 1995; Collins and Berge 1996; Gibson 1996; Zhu 1996; Kanuka and Anderson 1998; Rourke and Anderson 2000). Far from indicating weakness, the epistolary style, with its deliberate tentativeness and characteristic preference for qualification and personalization, is a strategy for reinforcing core purposes and values of conferencing: thoughtfulness, reflection, and continuing dialogue. Where the expository style may close off discussion prematurely (perhaps before shallow thinking is unmasked or misinformation corrected), epistolary strategies tend to encourage continued, deeper, and wider ranging exchanges (Fahy, Crawford, and Ally 2001). Where a rigorously expository conference environment may reward declamation (with minimal interaction), a more epistolary one is more likely to encourage the exchange of "interconnected and mutually responsive" messages (Gunawardena, Lowe, and Anderson 1997).

Differential use of qualifiers and intensifiers is a device for participants to present themselves in a personal way in online conferences and thus to create social presence in a communication environment that has been called linguistically "lean" (Garrison, Anderson, and Archer 2000) and an interpersonal "information desert" (Kilian 1997). The influence of these communicative forms may be subtle, but findings such as these suggest they are real and that they may constitute an important, if yet poorly understood, part of the gestalt of online distance learning. 


\section{References}

Abrami, P., and E. Bures. 1996. Computer-supported collaborative learning and distance education. The American Journal of Distance Education 10 (2): 37-42.

Anderson, T., and D. R. Garrison. 1995. Transactional issues in distance education: The impact of design in audioteleconferencing. The American Journal of Distance Education 9 (2): 27-45.

Anderson, T., L. Rourke, D. R. Garrison, and W. Archer. 2001. Assessing teaching presence in a computer conferencing context. Paper presented at the annual meeting of the American Educational Research Association, April 10-14, Seattle.

ATLAS.ti Ver. 4.1. www.atlasti.de

Ball, P. 2001. The next generation of optical fibres. Technology Review 104 (4): 55-61.

Blocher, M. 1997. Self-regulation of strategies and motivation to enhance interaction and social presence in computer-mediated communication. Ph.D. diss., Arizona State University. Available online at http://wwwlib.umi.com/dissertations/fullcit?50612

Collins, M., and Z. Berge. 1996. Facilitating interaction in computer mediated online courses. Retrieved June 12, 1999 from the World Wide Web: http://jan.ucc.nau.edu/ mpc3/moderate/flcc.html

Collison, G., B. Elbaum, S. Haavind, and R. Tinker. 2000. Facilitating online learning: Effective strategies for moderators. Madison, WI: Atwood.

Collot, M., and N. Belmore. 1996. Electronic language: A new variety of English. In Computer-mediated communication, ed. Susan C. Herring, 13-28. Philadelphia: John Benjamins Publishing Co.

DeSanctis, G., and R. B. Gallupe. 1987. A foundation for the study of group decision support systems. Management Science 33 (5): 589-609.

Fahy, P. J. 2001a. Addressing some common problems in transcript analysis. International Review of Research in Open and Distance Learning 1 (2). Available online at http://www.irrodl.org/content/v1.2/research.html\#Fahy

. 2001b. Epistolary and expository interaction patterns in a computer conference transcript. (Manuscript submitted for publication.)

Fahy, P. J., G. Crawford, and M. Ally. 2001. Interactional and structural patterns in computer conference (CMC) transcripts. International Review of Research in Open and Distance Learning 2 (1). Available online at http://www.irrodl.org/content/v2.1/fahy.html 
French, D., C. Hale, C. Johnson, and G. Farr, eds. 1999. Internet-based learning. London: Kogan Page.

Fulford, C. P., and S. Zhang. 1993. Perception of interaction: The critical predictor in distance education. The American Journal of Distance Education 7 (3): 8-21.

Garrison, D. R., T. Anderson, and W. Archer. 2000. Critical inquiry in a text-based environment: Computer conferencing in higher education. Internet and Higher Education 11 (2): 1-14.

2001. Critical thinking, cognitive presence, and computer conferencing in distance education. The American Journal of Distance Education 15 (1): 7-23.

Gibson, C. C. 1996. Collaborative learning in action via computer mediated conferencing. In Proceedings of the 12th annual conference on distance teaching and learning: Designing for active learning, 121-125. Madison: University of Wisconsin.

Gunawardena, C., C. Lowe, and T. Anderson. 1997. Analysis of a global on-line debate and the development of an interaction analysis model for examining social construction of knowledge in computer conferencing. Journal of Educational Computing Research 17 (4): 395-429.

Henri, F. 1992. Computer conferencing and content analysis. In Collaborative learning through computer conferencing: The Najaden papers, ed. A. Kaye, 117-136. Berlin: Springer-Verlag.

Herring, S. 1996. Two variants of an electronic message schema. In Computer-mediated communication, ed. Susan C. Herring, 81-106. Philadelphia: John Benjamins Publishing Co.

Hillman, D. C. A. 1999. A new method for analyzing patterns of interaction. The American Journal of Distance Education 13 (2): 37-47.

Kanuka, H., and T. Anderson. 1998. Online social interchange, discord, and knowledge construction. Journal of Distance Education 13 (1): $57-74$.

Kilian, C. 1997. F2F-why teach online. EduCom Review 32 (4). Available online at http://www.educause.edu/pub/er/review/reviewArticles/32431.html

King, J. 1998. Canadian Internet statistics: How many Canadians on-line? CanadaOne Magazine. Retrieved April 5, 2002 from the World Wide Web at http://www/canadaone.com/technology/Canadian_Internet_statistics.html

Kirkup, G., and C. von Prummer. 1990. Support and connectedness: The needs of women distance education students. Journal of Distance Education 5 (2): 9-31. 
Ridley, C., and A. Avery. 1979. Social network influence on the dyadic relationship. In Social exchange in developing relationships, ed. R. Burgess and T. Huston, 223-246. New York: Academic.

Rodino, M. 1997. Breaking out of binaries: Reconceptualizing gender and its relationship to language in computer-mediated communication. Journal of Computer-Mediated Communications 13 (3). Available online at http://www.ascusc.org/jcmc/vol3/issue3/rodino.html

Rourke, L., and T. Anderson. 2000. Exploring social communication in computer conferencing. Association for the Advancement of Computers in Education. Unpublished paper.

Rourke, L., T. Anderson, R. Garrison, and W. Archer. 1999. Assessing social presence in asynchronous text-based computer conferencing. Journal of Distance Education 14 (2): 50-71.

. 2001. Methodological issues in the content analysis of computer conference transcripts. International Journal of Artificial Intelligence and Education 12:8-22. Available online at http://rbl.leeds.ac.uk/ijaied/

Saba, F. 2000. Research in distance education: A status report. International Review of Research in Open and Distance Learning 1 (1). Available online at http://www.irrodl.org/content/v1.1/farhad.pdf

Savicki, V., D. Lingenfelter, and M. Kelley. 1996. Gender language style and group composition in Internet discussion groups. Journal of Computer-Mediated Communications 2 (3). Available online at http://www.ascusc.org/jcmc/vol2/issue3/oldsavicki.html

Still time for T1 and T3. 2001. PC Magazine 20 (6): 68.

Yates, S. 1996. Oral and written linguistic aspects of computer conferencing: A corpus based study. In Computer-mediated communication, ed. S. C. Herring, 29-46. Philadelphia: John Benjamins Publishing Co.

Zhu, E. 1996. Meaning negotiation, knowledge construction, and mentoring in a distance learning course. In Proceedings of selected research and development presentations at the 1996 national convention of the Association for Educational Communications and Technology, Indianapolis. ERIC, ED 397849. 
Copyright $\odot 2002$ EBSCO Publishing 